\title{
Extensive Reading in EFL Classroom at Secondary Schools in Bangladesh: Current Practices and Future Possibilities
}

\author{
Md. Zulfeqar Haider (Corresponding author) \\ Foreign Language Training Centre, Dhaka \\ Govt. Bangla College, Mirpur, Dhaka 1217, Bangladesh \\ Tel: 880-2805-5822Ｅ-mail: zhfahian@yahoo.com \\ Elina Akhter \\ National Academy for Educational Management, Dhaka \\ New Market, Dhaka-1205, Bangladesh \\ Tel: 880-171-824-8013Ｅ-mail: elina_akhter@yahoo.com
}

Received: March 9, 2012

Accepted: March 28, 2012 Online Published: May 3, 2012

doi:10.5539/ies.v5n3p126

URL: http://dx.doi.org/10.5539/ies.v5n3p126

\begin{abstract}
Extensive reading is being practiced in many EFL and ESL classrooms as an effective means for developing learners' reading as well as other related skills. This paper is based on a small-scale study that explores the current practices and future possibilities of using extensive reading in the EFL classrooms at the junior secondary schools in Bangladesh. The study reports the responses of 100 secondary English teachers on different aspects of using extensive reading tasks in the EFL classrooms of Bangladeshi schools. It is found that though the teachers of Bangladesh express positive beliefs about the benefits of extensive reading, the techniques they follow in their classrooms at present mostly encourage intensive reading. It is also evident that teachers who deal with extensive reading do not often follow the best practices in the classrooms. It is suggested in this study that extensive reading needs to be promoted in the Bangladeshi schools through coordinated efforts of all the stakeholders in the secondary education system. It is stressed that a combination of initiatives such as teacher training, awareness raising, curriculum reform and changing existing assessment format can promote the practices of extensive reading activities among the young learners.
\end{abstract}

Keywords: Extensive reading, EFL, Teacher’s role, Best practices, Bangladesh

\section{Introduction}

\subsection{Role of ER in Second Language Learning}

It is an undeniable fact that the ability to read in a foreign or second language is one of the essential skills required of people living in multilingual and international settings. Among the four macro skills of English, reading is often challenging for the learners to develop. Teaching reading is a complex task as it requires a combination of skills and sub skills that pervade enormously while processing information from a text. Moreover, the fact that different readers read a text with different purposes has led to the innovation of a variety of approaches or methods which are being practiced in many foreign or second language learning contexts.

In the area of Second Language Acquisition (SLA) two key approaches to teaching reading are widely followedIntensive reading and Extensive reading (ER). Intensive reading usually involves a slower process of reading of a relatively small amount of materials with a view to extracting specific information while extensive reading permits students to read a relatively vast amount of simpler texts mainly for getting pleasure. The second language curricula of most developing countries put stress mainly on intensive reading leaving the idea of extensive reading ignored. However, research findings on ER show that this method of reading can have a significant impact on learners' L2 development. (Hafiz and Tudor, 1989; Bamford, 1998, Horst, 2005; Mason and Krashen, 1997; Bell, 2001 and Hayashi, 1999). The fact that reading a great deal in the target language has positive impact on learning a language authenticates the benefits of ER. It has been argued that students who read a vast volume of texts in the target language become better and more confident readers; they write better, their listening and speaking abilities improve, 
and their range of vocabulary gets richer. In addition, they develop positive attitudes toward and increased motivation to learning the new language.

\subsection{ER in Bangladeshi Classrooms}

Although ER is proved to have yielded significant constructive outcomes in second or foreign language learning, the incorporation and practice of ER are almost nonexistent in the junior secondary EFL classrooms of Bangladesh. It is noteworthy that ER is mentioned as one of the optional activities for the students in the curriculum document of National Curriculum and Textbook Board (NCTB). However, the curriculum document of NCTB does not say anything explicitly regarding the nature and method of dealing with ER in the classroom (NCTB, 1999). Thus, though ER is mentioned in the curriculum, many of its specific features (such as what books to teach or how to teach) are not spelt out in details. As a result, the way ER is being practiced in the classes does not conform to the best practices for teachers and learners.

A series of English storybooks titled 'Rapid Reader' are selected to introduce extensive reading to the Bangladeshi learners of grades six, seven and eight, These collections of popular classics in retold versions are compiled by the local ELT experts and textbook writers of NCTB. Each book contains several different stories in simplified English. The very title of the series 'Rapid Reader' makes it clear that they have been supplied with the core English textbooks for the purpose of promoting Extensive Reading.

\section{Objectives and Methodology of the Study}

The main objectives of the study are to investigate into the current practices of ER in Bangladeshi secondary classrooms and to identify the areas to be improved. The study explores the teaching-learning process through which the students of junior secondary schools are engaged in extensive reading in Bangladesh. The findings of this study are fundamentally qualitative. The data was collected through a questionnaire having 14 closed-ended and two open ended questions (Appendix 1). The respondents were selected from a group of trainee-teachers who teach English in the secondary schools in Dhaka city and the surrounding areas. The teachers were attending an in-service training program titled "Continuous Professional Development (CPD) for the Teachers of English" at the National Academy for Educational Management (NAEM), Bangladesh. A total of 100 participants responded to the questionnaire. The respondents were selected on a purposively-random basis.

\section{Literature Review}

\subsection{Intensive versus Extensive Reading}

Intensive reading means reading of a short text quickly to obtain detailed meaning from it. It aims at developing various features of reading abilities- such as identifying main idea, specific information or text connectors and enhancing learners' vocabulary and grammar. It may often involve translation exercises, particularly in a foreign or second language learning situation. On the other hand, extensive reading involves reading longer texts for understanding the general idea with more emphasis on meaning than on the form (Carrell and Carson, 1997). In case of ER the students are not usually required to display comprehension to a degree as detailed as they would in an intensive reading program. Thus, "ER is a fluency oriented activity, mainly calling for a global understanding of a text” (Grellet, 1981).

\subsection{Features of Extensive Reading}

Walter (2003) defines extensive reading as reading of texts that are chosen by the learners themselves and that do not seem problematic either. Davies (1995, p. 329) provides a detailed account of extensive reading in the context of ELT classroom. He compares an extensive reading program, in an ELT course to an additional class-library idea where students are provided not only with a large number of books but also with enough time, motivation and encouragement to read them. He concludes that as there is no pressure of formal assessment or marking in an ER program, the pupils do not have to worry about competing with others. Thus, it is hoped that the students get pleasure in such a favorable reading atmosphere. He further opines that in an ER program learners read extensively not only for gathering information but also for getting pleasure and the reading texts have to be simple so that the learners do not need to use dictionaries.

Renandya and Jacobs (2002) sorted out some distinct characteristics of ER as mentioned by other linguists which are as follows:

- Students read a large amount of material

- Students usually choose what they want to read

- $\quad$ Reading materials vary in terms of topics and genre 
- The materials students read is within their level of comprehension

- Students usually take part in post-reading activities

- Teachers read with their students, thus, modeling enthusiasm for reading

- Teachers and students keep track of students' progress

There have been some other reading programs having similar features of extensive reading but with different names. Some examples are the Uninterrupted Sustained Silent Reading (USSR), Drop Everything and Read (DEAR), Silent Uninterrupted Reading for Fun (SURF) and the Book Flood Approach.

\subsection{Benefits of Extensive Reading}

Over the past decade or so, there have been numerous studies that inform that extensive reading has benefited learners to a great extent. To start with, ER enhances language learning in many linguistic areas. While being exposed to a vast number of reading materials, L2 learners avail an opportunity to overcome their long prevailing common spelling mistakes, expand vocabulary and increase knowledge of grammar and text structure. This clearly underpins what Grabe and Stoller (2002) stated that the entire amount of exposure to L2 reading influences the development of L2 learning.

Since students do not require obtaining scores or marks in an ER program, they can read with a relaxed mind and, thus, can enjoy reading. Besides, ER helps learners enhance their knowledge of the world as the reading involves a variety of topics and subjects.

Another important benefit that ER provides the L2 learners is aside from mastering the reading skill, they improve their writing skill as well. For instance, in countries where there are shortages of efficient L2 teachers, learners are often misguided or left with poor writing qualities. So, when the learners read extensively, they very often come across some common and standard structures of writing which they may, even to their subconscious mind, be able to internalize and thus develop their writing skill.

Moreover, it is usually hoped that after achieving a certain level of proficiency by the learners through ER, there is a higher possibility of forming a reading habit that might become a pastime in the later stages of their life. ER is very likely to build and strengthen confidence among the L2 learners in the long run. As a result, the learners are expected to grow a positive attitude toward $\mathrm{L} 2$ reading.

The importance of extensive reading in learners' L2 development is further highlighted by Elley's statement. He states that "Book flood" (in other words, extensive reading) has been proved as a highly potential strategy for raising literacy level in developing countries (Elley, 2000). It has been trialed and evaluated in the schools of Fiji, Nuie Island, Sri Lanka, Pakistan, South Africa and several other countries. The evidence shows that the rate of reading acquisition in those countries can be doubled with the introduction of "Book flood" comprising 100 high interest books per class and short teacher training sessions. The incorporation of this technique has benefited consistently across different cultures, vernacular and age levels where children have been found with improvement in their writing, listening comprehension and related language skills. In a study on ESL students in Philippines, it has been found that 60 students who used to fail in reading following traditional method made significant gains over six months of silent reading which is a key feature of extensive reading (Elley, 2000). Thus, Elley \& Manghubai's (1983) book flood project remains by far the most convincing evidence of the value of reading books for pleasure and in quantity.

The benefits of ER can further be attested by Bell's study. Bell (2001) conducted a study between two groups of elementary level learners $(n=26)$ at the British Council English Language Centre in Sana'a, Yemen. The learners were exposed to differing reading programs. The experimental group $(n=14)$ was placed in an extensive reading program consisting of class readers, a library of books for students to borrow, and regular visits to the library providing access to a much larger collection of graded readers (up to 2000 titles). On the other hand, the control group $(n=12)$ received an entirely different reading program which was intensive in character that involved reading of short passages and completion of tasks designed to assess knowledge on grammar, lexis, and rhetorical patterns. The study took over a period of two semesters and the reading program covered one quarter of the total class time (36 out of 144 hours). The result found that the gains in reading speeds were four times greater in the extensive group while the gains in reading comprehension were three times greater in the control group. The finding also indicates the problems that lie intrinsically with intensive reading approaches. Intensive approaches, because they focus on language manipulation rather than developing reading, tend to inhibit reading improvement among learners at low proficiency levels. Extensive reading in contrast, seems to liberate the learner from slow reading speeds, and lead to genuine comprehension of what is being read. 


\section{Findings and Discussions}

\subsection{Purpose of Reading}

In their responses to the question "Why do your students need to read an additional English book?" $79 \%$ teachers report that the students read the books on ER only to pass the examination while $21 \%$ say that the students also get pleasure while they read. This finding is rather unsatisfactory as only a small number of students are reported to get pleasure from ER whereas a great majority of students are reported to read for passing examinations. This indicates a major problem with the learners' attitude towards extensive reading activities. Usually, in most Bangladeshi schools, examination questions are set from the 'Rapid Readers' alongside the main textbook. In a test of 100 marks10 to 20 marks are allocated on the basis of students' reading of the 'Rapid Readers'. Since students are often too worried about passing the exams, they are most likely to miss the care-free environment that they should have in order to enjoy their extensive reading texts.

\subsection{Problems Faced by Students with Extensive Reading}

The harmful effect of exam pressure is also very succinct when it is found that most of the students cannot complete reading all the stories as they become too concerned about reading test. In their responses to question no. 3 and 4 , $57 \%$ teachers opine that the students cannot complete all the stories because they take too much time on reading a single story to get good scores in the exam. 26\% participants believe that their students fear reading in English. The rest of the teachers think that the students are reluctant to read, as the language is very hard. Under the circumstances, it is worth mentioning that in ER students are encouraged to stop reading if the materials are not interesting or if they find the texts too difficult. In any ER program the students are supposed to read a vast amount of reading materials or stories. However, it is evident that the secondary level students at Bangladeshi schools cannot complete all the stories in most cases. Hence, the teachers often chose to select only a certain numbers of stories from the selected books and only those stories are considered for setting examination questions in the final test.

\subsection{Selection of Stories}

In an extensive reading program students usually choose the stories by themselves. However, from the study it is revealed that all the stories are chosen by the teachers. In their responses to question no 5, $100 \%$ teachers say that they chose the stories for their students to read and the students do not have their own choice of selecting something to read. This is again an erroneous method, which hinders the success of ER. The practice of allowing the students to choose the topics they wish to read about is necessary to make them interested about ER.

\subsection{Post Reading Activities}

Instead of setting questions from the 'Rapid Reader' in the exams, interesting post-reading activities are recommended as follow-up activities. Such activities are carefully prepared to sustain the interest of learners. Typical reading lesson questions such as comprehension questions and summary writing are to be avoided as ER is not intended to assess learners' thorough understanding of the text. The study shows that although post-reading activities are conducted by most of the teachers, 78 out of one hundred teachers mention only comprehension questions as the only activity they ask students to do after reading the stories while $14 \%$ mention summary writing. Only 8 teachers say that they ask students to copy interesting words and expressions into a notebook after they have read a story. In fact, setting too many activities may spoil the idea of reading for pleasure and thus blemish the very objectives of extensive reading. Moreover, the activities should not be such difficult that the students keep "squeezing the text dry" (Grellet, 1981. p10)

\subsection{Methods of Reading}

In order to make ER successful, silent reading is preferred. Again, apart from monitoring teachers also should read out the stories to encourage their students. However, it has been found that while 83 teachers tell their students to read the stories aloud, only 17 ask their students to read silently. Only a small number of teachers have found who read some parts of the stories aloud to their students.

\subsection{Facilitation of Reading}

Another weakness regarding the way the Bangladeshi teachers deal with extensive reading is unfolded as $67 \%$ teachers report that students read most part of the stories at their home while only 33 teachers say that they facilitate and monitor the whole reading in the class. There are no evidence of teachers preparing the students with the necessary help for encountering the text on their own.

\subsection{Benefits of Extensive Reading}

While commenting on the benefits of extensive reading programs $89 \%$ teachers report that their students learn a lot 
of vocabulary and the rest of them find their students improving their writings too. No students have been found to have 'mastered' the rules of grammar following the reading of the 'Rapid Readers'. This finding necessitates the proper handling of ER so that the number of students benefited from ER is increased.

\subsection{Teachers'Role}

One of the open ended questions (question 15) in the questionnaire was intended to generate teachers' perception of their role in conducting an extensive reading program. It is opined by the respondents that teachers' role is to monitor whether all the students read the maximum number of books in the allotted time. Almost all the teachers believe that they are the only persons who can make ER taking place successfully in the classroom. Despite the limited resources teachers themselves can take some small initiatives to promote ER. Even some teachers suggest that they can try to collect good story book or newspapers articles for their students in schools where it is not financially possible to ensure the availability of enough and interesting books for the students to read.

Some other teachers suggest that they also can encourage their students to set up a personal library. The students may find it convenient and thus be motivated when they are adviced to look for the second-hand books for the lowest price. Students can bring books from their own collection into their class and exchange among themselves. Thus, the teachers can introduce a swap scheme. To avoid any mismanagement, one of the students can be appointed as a 'librarian' who will note all the details of borrowing. When it becomes successful, the program can also be expanded at a larger scale. Thus, inter-class book-loan schemes can be introduced to promote extensive reading.

\section{Recommendations}

The recommendations are made on the basis of teachers' responses to the open ended questions (question no. 15 and 16) set in the questionnaire. Here the teachers give views on the problems they face with conducting extensive reading programs at their schools and also suggest ways to overcome them.

Most of the respondents are with the view that in Bangladesh the implementation of extensive reading is possible with combined efforts of all the stakeholders involved in education sector. For example, almost all the teachers express the belief that the role of Ministry of Education (MoE), NCTB, the school authorities, teachers, students and parents are undeniably essential to make extensive reading approach a success in Bangladeshi classrooms. They suggest that the MoE along with its other implementing agencies may launch mid and long term projects to weave ER into the ELT curriculum of both primary and secondary education sectors and provide every school with sufficient funds for buying books.

The respondents also put emphasis on the importance of setting up libraries both in and outside the school campus. A library is unquestionably an indispensable part of a school. That is why at least a mini library can be set up in all institutions. To make it a success, donations can be raised from the School Management Committee (SMC) members. Since the class size in Bangladesh is usually large, comprising not less than 60 students (in some schools it may exceed 60), every school library needs a good collection of books with a variety of titles. The teachers believe that students of a particular class can be divided into two or three (it depends on the class size) small groups and only one group may visit the library once a week after the school break. As per the teachers, one hour of reading per week is sufficient for the students. This will be a fruitful hour for the students because the teacher will be able to facilitate each learner's reading while paying attention to a small group of students at a time.

In Bangladesh there is a scarcity of efficient English teachers. As a result, the teachers remain terribly busy with other works aside from classroom teaching. Under these circumstances, teachers working hard for ER should be provided with some extra allowances or incentives. The teachers also feel the need of professional development training on ER, for instance, on the benefits and techniques of conducting ER. Grabe and Stoller (2002) rightly state that teachers having a good understanding of the importance of motivation, interest and self-esteem can determine the factors that motivate the students and nurture better attitudes within them towards reading.

Furthermore, the teachers suggested some classroom-based strategies for involving the students in extensive reading tasks. These include asking students to write a book report or make a presentation on a selected book as post-reading activity. Apart from this, teachers can tell the learners to keep a diary on a given book as they read it and then discuss with their classmates on regular intervals. Besides, the students can copy some interesting and new words and write some useful expressions in a notebook. This should not be difficult for them as they often do so in their L1 reading especially when they take part in "Boi Pora Kormosuchi (Book Reading Program)" organized by The World Literature Centre Of Bangladesh.

\section{Conclusion}

The use of extensive reading for developing students' language skills is a relatively new phenomenon in the teaching-learning context of Bangladesh. The teachers, the curriculum experts as well as the testing authority have a 
concerted role to play for making extensive reading an effective means of teaching English at the secondary schools of Bangladesh. This study throws some lights on the current practices of dealing with extensive reading in Bangladeshi junior secondary schools. Though the findings do not present a very encouraging picture of using extensive reading in the classroom, it has pointed out some areas of concern and suggested ways for overcoming them. Educating the teachers and others concerned on useful techniques of dealing with extensive reading can play a vital role in promoting reading among the learners. This process can also be harnessed by raising awareness among the parents who often see extra reading as wastage of time. This can be done through professional training for teachers and awareness raising workshops for guardians and other stakeholders.

\section{References}

Anderson, N. (2003). Reading. In Nunan, D (Ed). Practical English Language Teaching. McGraw-Hill, New York.

Bamford, J., \& Day, R. (1998). Extensive reading in the second language classroom. Cambridge: Cambridge University Press

Bamford, J., \& Day, R. 1997. Extensive reading: What is it? Why bother? The Language Teacher, 21(5)

Bell, T. (2001). Extensive reading: Speed and comprehension. The Reading Matrix 1. [Online] Available: http://www.readingmatrix.com/archives/archives_vol1_no1.html

Carrell, P.L, \& Carson, J.G. (1997). Extensive and intensive reading in an EAP setting. English for Specific Purposes, 16, 47-60.

Elley, W, B. (2000). The potential of book floods for raising literacy levels. International Review of Education. Netherlands: Kluwer Academic Publishers.

Elley, W.B., \& Manghubai, F. (1983). The effect of reading on second language learning. Reading Research Quarterly, 19(1), 53-67.

Grabe, W \& Stoller, F. (2002). Teaching and researching reading. UK: Pearson Education.

Grellet, F. (1981). Developing reading skills. Cambridge University Press: Cambridge.

Hafiz, F.M., \& Tudor, I. (1989). Extensive reading and the development of language skills. ELT Journal, 43(1), 5-13.

Hayashi, K. (1999) Reading Strategies and Extensive reading in EfL classes, RELC Journal, 30(2), http://dx.doi.org/10.1177/003368829903000207

Horst, M. (2005). Learning L2 vocabulary through extensive reading: A measurement study. The Canadian Modern Language Review, 61, 355-382.

Mason, B., \& Krashen, S. (1997). Extensive reading in English as a foreign language. System, 25, 91-102.

NCTB. (1999). Curriculum and syllabus document: Class 6-8, National Curriculum and Textbook Board, Dhaka, NCTB

Renandya, W, A., \& Jacobs, G, M (2002). Extensive reading: Why aren’t we all doing it? In Richards, J, C \& Jacobs, G, C. (Eds), Methodology in language teaching : An anthology of current practice. Cambridge: Cambridge University Press.

Tindale, J. (2003). Teaching Reading. National Centre for English Language Teaching and Research. Sydney, Macquarie University.

Wallace, C. (2001). Reading. In Carter, R \& Nunan, D (Eds).The Cambridge guide to teaching English to speakers of other languages. Cambridge: Cambridge University Press.

Walter, H. C. (2003). Reading in a second language. [Online] Available: http://www.llas.ac.uk/resources/gpg/1420

Yamashita, J. (2004). Reading attitudes in L1 and L2 and their influence on extensive reading. Reading in a Foreign Language, 16 (1). [Online] Available: http://www.nflrc.hawaii.edu/rfl 


\section{Appendix 1: Questionnaire for teachers}

(Please answer all questions. For questions 1-18 tick your chosen answer)

1. Apart from the English For Today textbook what other books do your students have to read in English in your institution?

$$
\begin{array}{ll}
\text { o } & \text { the 'Rapid Reader' } \\
\text { o } & \text { other selected books } \\
\text { o } & \text { both of these } \\
\text { o none of these }
\end{array}
$$

2. Why do your students need to read those additional English books?

$$
\begin{array}{ll}
0 & \text { to pass the exams } \\
0 & \text { to get pleasure } \\
0 & \text { both }
\end{array}
$$

3. Are the students able to finish reading all the stories within the allocated time?

$$
\begin{array}{ll}
\text { o } & \text { Yes, always } \\
\text { o } & \text { sometimes } \\
\text { o } & \text { No }
\end{array}
$$

4. If students can't finish their reading in time, why they can't?

o They take much time to read for exam needs

o They do not get pleasure

o The books are too difficult to read

o They fear reading in English

5. In your school all the texts for extensive reading are chosen by-
0 The teachers
o The students
o The syllabus committee

6. Do you set questions for the exam from the Rapid Readers?
o yes
o No

7. What marks do you allocate for the questions set from the Rapid Readers?
o $\quad 10-15$
o $15-20$
o $21-25$
o $26-30$
o above 30

8. What sorts of questions do you set in the exam?
o Comprehension question
o Writing summary
o Questions of vocabulary

9. How do you teach your students to read those books?

$\begin{array}{ll}0 & \text { to read silently } \\ 0 & \text { to read aloud in turns }\end{array}$

10. How do you help students with their reading? 
o You set tasks for students and ask them to read at home

o You read some parts in front of them.

o You just monitor.

11. Do you give your students any task in the class after they have finished reading?

0 yes, always

o most of the time

o not always

o never

12. If yes, what sort of activities do you give?

o Writing a summary

o learning unknown words and phrases

o Answer comprehension questions

13. Do you think 'Rapid Reader' helps the students much to improve their English?

o Never

o sometimes

o usually

o most of the time

o always

14. If yes, how are they improving?

o They learn a good number of new words

o They become good in grammar

o They improve their writing skill.

(Please write your answers here)

15. As a classroom teacher, what role can you play to implement ER with your students?

16. What are your suggestions to make ER successful in Bangladeshi schools? 